\title{
French Journals in Flux
}

\author{
from our Paris Correspondent
}

FOr a long time now it has been widely known that French scientific publishing is in a bad way. So it could be foreseen that, in the general movement towards reforming the universities which was begun last May, the Government would start thinking about taking measures to remedy this situation. A first timid step has just been taken with the formation of a working party made up of personalities from the scientific world, specialist publishers and representatives of government departments concerned (education, scientific research, industry). The job of this commission is to analyse the problem and offer recommendations on what is to be done. Putting these recommendations into practice could be opposed by a solid body of interested parties, but the Government seems to have decided to put an end to inertia and ill will.

The two most urgent quastions concern theses and scientific journals. In France, the doctoral thesis (especially in the humanities) is a formidable undertaking which necessitates often 10,12 or even 15 years work on the part of candidates. These scholarly monographs, the subject of which is more often determined by personal whim than by the importance of the theme, are often devoid of what little interest they might have had at the moment of final publication. This system, which weighs heavily on the future holder of a doctorate (who is also prevented from carrying on more fruitful research during the most creative time in his career) is also costly for the state, which partly subsidizes the publication of these huge works. The system has often been criticized. There is reason for thinking, however, that it is coming to an end. Among the proposed solutions, the best would certainly be to treat as a thesis a collection of articles published in specialist journals. This would allow the scientific world to reap the benefits of a candidate's work as he is doing it, not 10 years after. There is also some talk of publishing theses only in microfilm form and reserving publication in book form only for when the author agrees to a strict limit in length (for example, 250 pages) or for when the subject seems to justify a wider audience than the narrowly specialist one.

Solving the problem of scientific journals will create many more difficulties and provoke many more arguments. At present, financial aid from public funds is spread over a large number of journals, many of which are either mediocre in standard or repetition. Furthermore, while it is the ambition of every university lecturer to "have his own journal" and to obtain the necessary capital to publish it, no one seems to have given much thought to marketing these periodicals. The capital set aside to subsidize all these journals, while quite considerable, is not ruinous for the state. But is it of any use ? The National Scientific Research Centre (CNRS) will have allocated in 1968 about $15,000,000$ new francs (roughly 4 per cent of its budget) to some 250 journals, some of which are of doubtful interest. The more clear-headed scientists foresee drastic remedies; simply, the straightforward closing down of some journals and the merging of several others. A CNRS commission, having studied the matter in 1966, has already formulated conclusions along these lines. The Government will certainly be favourably disposed towards such measures. But are they adequate?

The fundamental consideration lies in the quality of the journals. Through not publishing enough first class articles, many French journals are completely unknown to foreign research workers. The fact that they are usually not provided with English résumés does not make their circulation in international scientific circles any easier. The fact is that, in many fields, there are just not enough high quality French research workers to feed material regularly into the specialist periodicals. As for foreign authors, they generally prefer, both for prestige and language reasons, to publish their work in English language journals. Certain reformers have expressed their desire to see the establishment, among other things, of a French Nature. It has soon become apparent that this proposition could not be carried out.

If there is no real solution as far as France itself is concerned, some people are now thinking that there is, on the other hand, a solution on a European level, provided, of course, that it is agreed that there should be no one predominant language. The most recent attempt in this direction is, without doubt, that of the Annales d'Astrophysique, whose example should serve to make scientists in other fields think a bit. Dr Steinberg, managing editor of the Annales, had for a few years been feeling somewhat discouraged by the lack of effectiveness of his work. Circulation was poor (750 subscribers... some free), the average level of articles inadequate, deadlines were difficult to meet as contributors were either too slow or too careless, and Dr Steinberg noticed a depressing rate of quotation in analogous foreign journals (Astrophysical Journal, Monthly Notices of the Royal Astronomical Society).

Taking up his pilgrim's cloak, therefore, he set out to persuade a certain number of foreign colleagues-each of whom was experiencing similarly depressing events - to pool their efforts. This plan will now bear fruit. A new monthly journal, grouping together the existing national journals, ought to see the light of day at the beginning of 1969. Published in English, French and German, with the title Astronomy and Astrophysics, $A$ European Journal, it will be the result of cooperation between the Scandinavian, the Dutch, the German and the French. Its editorial committee will, of course, be multinational.

One can obviously ask why this new Common Market in scientific information also leaves Great Britain at the door, especially as it was the Royal Astronomical Society which, we are told, first raised the idea of a European journal at the general assembly in Prague of the International Astrophysical Union. It appears that this time General de Gaulle is not to blame. The Royal Astrophysical Society took part in the preliminary discussions, but, although keeping a benevolent eye on the proceedings, it refused, it is said in Paris, to contemplate sacrificing for the time being its Monthly Notices on the European altar. 